\title{
Cardiac Abnormalities Related to 10q26 Chromosomal Deletion in
}

\section{Neonate}

\author{
Ehsan Aghaei Moghadam ${ }^{1}$, Maryam Nikoufar ${ }^{2,}{ }^{*}$, Azin Ghamari ${ }^{3}$ and Mohammad Taghi Majnoun ${ }^{2}$ \\ ${ }^{1}$ Assistant Professor of Pediatric Cardiology, Tehran University of Medical Sciences, Thran, IR Iran \\ ${ }^{2}$ Pediatric Cardiology Fellow, Tehran University of Medical Sciences, Thran, IR Iran \\ ${ }^{3}$ Medical Student, Tehran University of Medical Sciences, Thran, IR Iran \\ "Corresponding author: Maryam Nikoufar, Pediatric Cardiology Fellow, Tehran University of Medical Sciences, Thran, IR Iran, E-mail: mary_nikoofar@yahoo.com
}

Received 2017 February 20; Revised 2017 May 04; Accepted 2018 June 06.

Chromosomal microdeletions are usually accompanied with medical and developmental concerns. Although same microdeletions obviously are not symptomatic during childhood, some other deletions are related to clinical manifestations in neonates such as growth and neurodevelopmental delay, feeding difficulties, hypotonia, and motor developmental defects (1). Cardiovascular anomalies have been revealed to affect up to half of all neonates born with a 10q26 microdeletion (2). The described case was a female neonate (11 month, 15 days) with the birth weight of $2400 \mathrm{~g}$ that was born through cesarean section from a 25-years old healthy mother (G3P2Ab1L1). The patient was the second child of the family with no abnormal condition in first child. She was evaluated from birth because of appearing cardiac murmurs that was assessed by echocardiography leading the diagnosis of Ventricular septal defect plus pulmonary stenosis. At the age of 6 months, the patients was revisited due to pulmonary infection and admitted to neonatal intensive care unit but without requiring mechanical ventilation. Concurrently, the patient was worked-up because of septic arthritis of the hip joint simultaneously with neurodevelopmental delay. In this regard, according to the chromosomal study, deletion in the location of 10q26 was detected. Liver function test and other metabolic work-ups were all normal. Although patient could sit with help in the month of 9, she was unable to stand without helping. In physical examination, she seemed to be hypotonic and flaccid with the weight of $6500 \mathrm{~g}$, and head circumference of $39.5 \mathrm{~cm}$. In echocardiography assessment, the following findings were evident: perimembranous VSD size of $4.5 \mathrm{~mm}$, a left to right shunt, severe supravalvular and valvular pulmonary stenosis, with a gradient of $75 \mathrm{mmHg}$ and confluent good size of pulmonary artery branches. A bicuspid pulmonary valve with the size of $9.2 \mathrm{~mm}$ was also detected. The diameters of the left and right pulmonary arteries were also estimated to be $8 \mathrm{~mm}$ and $7 \mathrm{~mm}$ respectively. Because of the pointed evidences, the patient underwent open heart repairing surgery with the aim of total VSD closure, PDA ligation, and pulmonary valvulotomy with supra-annular patch. After surgical correction and recovery, the patient was discharge with a clinical good condition with recommending neurological follow-up for neurodevelopmental delay. 10 26 microdeletion syndrome was initially described by Lewandowski et al. (3). It has been recently showed that the specific change in chromosome 10 related to heart defects included a de novo approximately $12.5 \mathrm{Mb}$ terminal deletion 10q26.12 -> qter (4). The most frequent conditions observed in the affected children including persistence of prenatal cardiac structures such as PDA followed by VSD and ASD that commonly no needing surgical intervention and thus can be self-limited (5). It can be concluded that in neonates with multiple cardiac and noncardiac defects, chromosomal assessment by specific tests such as FISH test may result in discovering some deletions or structural polymorphisms led to accurately diagnosis of the source of syndrome and thus to better management of patient.

\section{References}

1. Watson CT, Marques-Bonet T, Sharp AJ, Mefford HC. The genetics of microdeletion and microduplication syndromes: an update. Annu Rev Genomics Hum Genet. 2014;15:215-44. doi: 10.1146/annurev-genom091212-153408. [PubMed: 24773319]. [PubMed Central: PMC4476258].

2. Bruneau BG. The developmental genetics of congenital heart disease. Nature. 2008;451(7181):943-8. doi: 10.1038/nature06801. [PubMed: 18288184].

3. Lewandowski RC Jr, Kukolich MK, Sears JW, Mankinen CB. Partial deletion 10q. Hum Genet.1978;42(3):339-43. [PubMed: 669716].

4. Gunnarsson C, Graffmann B, Jonasson J. Chromosome $\mathrm{r}(10)(\mathrm{p} 15.3 \mathrm{q} 26.12)$ in a newborn child: case report. Mol Cytogenet. 2009;2:25. doi: 10.1186/1755-8166-2-25. [PubMed: 19968867]. [PubMed Central: PMC2794276].

5. Wulfsberg EA, Weaver RP, Cunniff CM, Jones MC, Jones KL. Chromosome 10qter deletion syndrome: a review and report of three new cases. Am J Med Genet. 1989;32(3):364-7. doi: 10.1002/ajmg.1320320319. [PubMed: 2658586]. 


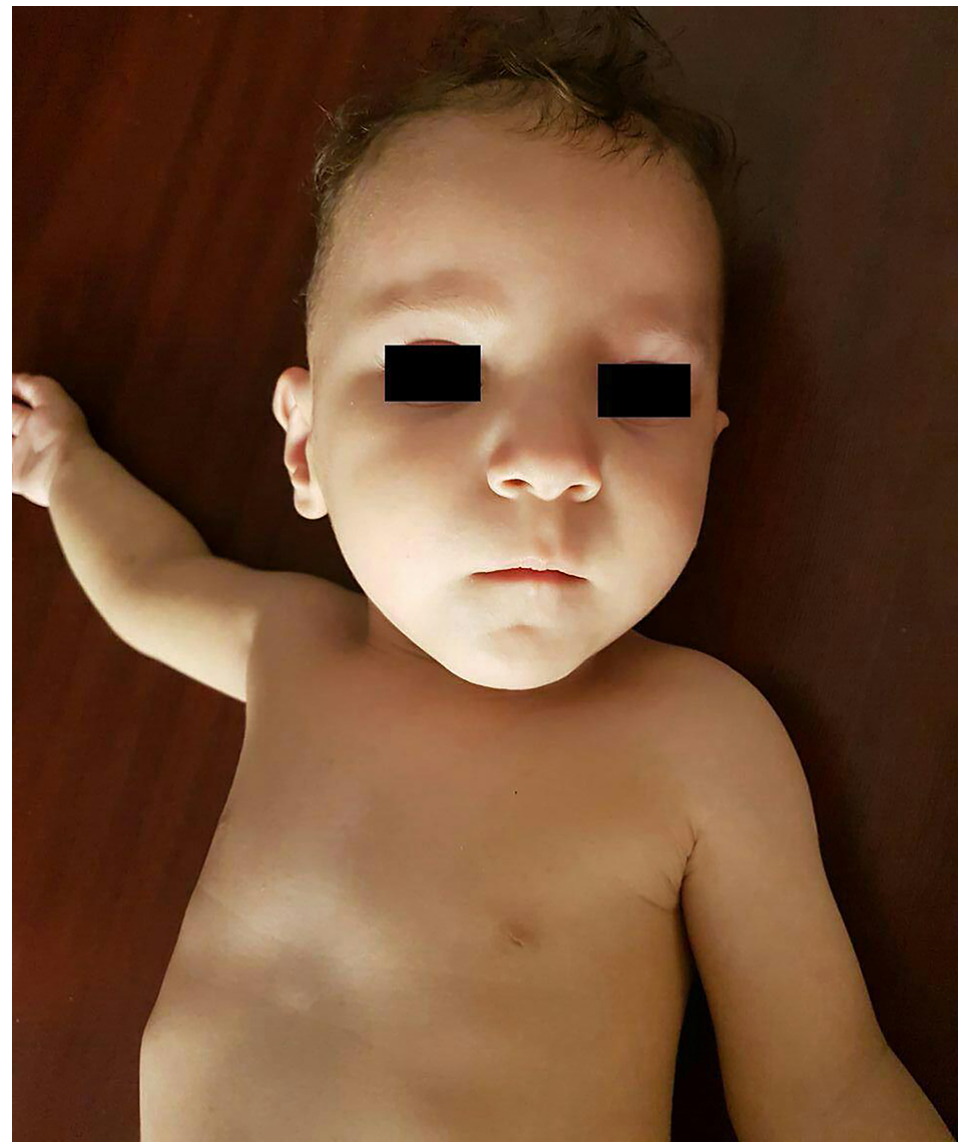

Figure 1. A general picture of the neonate suffered from heart defects related to $10 \mathrm{q} 26$ chromosomal deletion

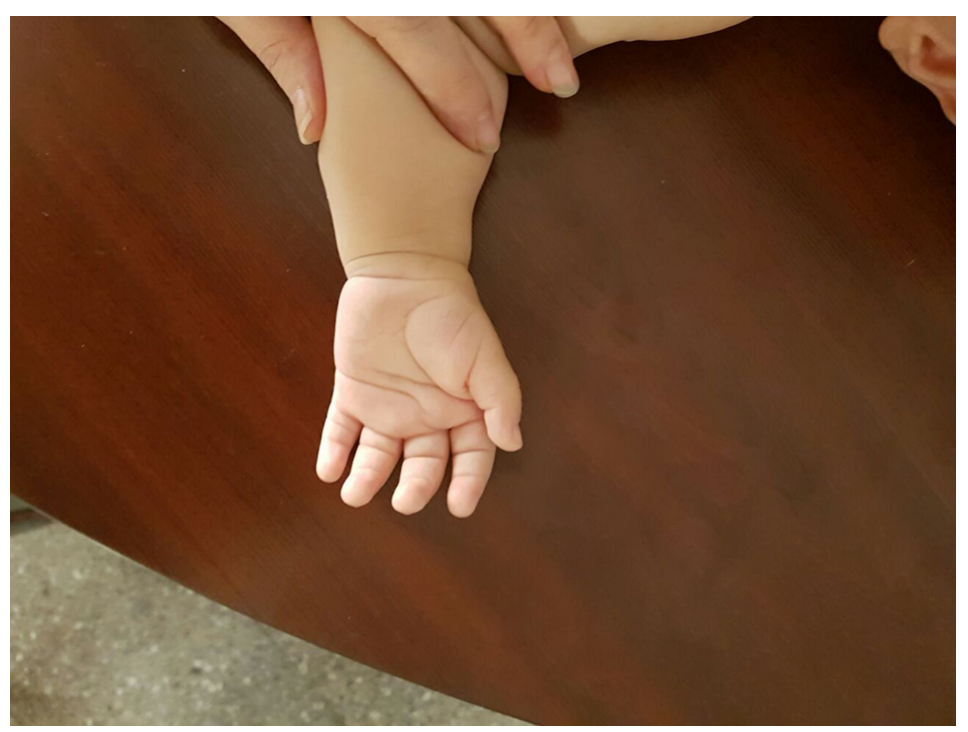

Figure 2. A picture of the hand in the neonate suffered from heart defects related to $10 \mathrm{q} 26$ chromosomal deletion 